\title{
Food insufficiency is associated with depression among street-involved youth in a Canadian setting
}

\author{
Julia Goldman-Hasbun ${ }^{1}$, Ekaterina Nosova' ${ }^{1}$, Kora DeBeck ${ }^{1,2}$, Lucia Dahlby ${ }^{1}$ and \\ Thomas Kerr ${ }^{1,3, *}$ \\ 'British Columbia Centre on Substance Use, 400-1045 Howe Street, Vancouver, BC, V6Z 2A9, Canada: ${ }^{2}$ School of \\ Public Policy, Simon Fraser University, Vancouver, BC, Canada: ${ }^{3}$ Department of Medicine, University of British \\ Columbia, Vancouver, BC, Canada
}

Submitted 30 September 2017: Final revision received 23 July 2018: Accepted 3 September 2018: First published online 11 0ctober 2018

\begin{abstract}
Objective: Food insufficiency, defined by the experience of hunger, is known to be prevalent and a source of health-related harm among-street involved youth, but little is known about its relationship with depression in this population. Therefore, we sought to assess the association between food insufficiency and symptoms of depression among a cohort of street-involved youth.

Design: Multivariable logistic regression was used to assess the relationship between food insufficiency, defined as being hungry but not having enough money to buy food, and depression as measured by the Center for Epidemiological Studies Depression (CES-D) scale.

Setting: Data from April 2006 to November 2013 were derived from the At-Risk Youth Study (ARYS), a prospective cohort of street-involved youth who use illicit drugs in Vancouver, Canada.

Subjects: There were 1066 street-involved youth enrolled in the study, including $340(31.9 \%)$ females.

Results: Of 1066 youth enrolled in the study, 724 (67.9\%) reported some food insufficiency and 565 (53.0\%) met criteria for depression. Compared with youth who did not report food insufficiency, those who reported often experiencing food insufficiency had a higher likelihood of reporting depression (adjusted $\mathrm{OR}=2 \cdot 52 ; 95 \%$ CI $1.74,3.67)$, as did those who reported sometimes experiencing food insufficiency (adjusted OR =1.99; 95\% CI 1.47, 2.70).

Conclusions: Food insufficiency was prevalent and associated in a dosedependent trend with symptoms of depression among street-involved youth in our setting. Findings highlight the need to address the nutritional and mental health needs of youth and identify pathways by which food insufficiency may contribute to depression among vulnerable populations.
\end{abstract}

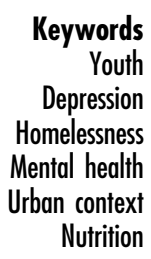

Youth and young adults who live or work on the street contend with an array of health and social challenges, including engagement in injection drug use ${ }^{(1)}$, sex work $^{(2)}$ and substandard housing(3). In turn, these challenges have resulted in elevated morbidity and mortality among this population relative to other youth ${ }^{(4,5)}$. Street-involved youth also frequently struggle to obtain nutritious and reliable food supplies ${ }^{(6,7)}$, which has been associated with nutritional deficiencies ${ }^{(8-10)}$, kidney disease $^{(11)}$, poor mental health ${ }^{(12,13)}$, obesity ${ }^{(14)}$ and diabetes $^{(15)}$ in high-risk populations and in the general adult population. In addition, mental illness, such as major depressive disorder, disproportionately affects streetinvolved youth ${ }^{(16,17)}$.
Food insecurity is a broad conceptual term referring to the inability to acquire, through socially acceptable means, adequate food supplies for a healthy life ${ }^{(18)}$. Food insufficiency is an individual-level stage of food insecurity that is defined by the experience of hunger ${ }^{(19)}$. Previous studies have found associations between experiences of food insecurity and depressive symptoms among selected populations, such as people who are HIV-positive ${ }^{(20,21)}$, adults who use injection drugs ${ }^{(22)}$, recent mothers ${ }^{(23)}$, individuals with diabetes ${ }^{(24)}$ and youth ${ }^{(25,26)}$. However, to our knowledge, there has been no investigation of the relationship between food insecurity and symptoms of depression among populations of street-involved youth who use illicit drugs. 
Drawing on a prospective cohort study of streetinvolved youth who use illicit drugs in a Canadian setting, we undertook the present study to examine the relationship between food insufficiency and symptoms of depression, including changes in depression with rising levels of food insufficiency.

\section{Methods}

The At-Risk Youth Study (ARYS) is an open prospective cohort study of street youth who use illicit drugs based in Vancouver, Canada. Youth aged 14-26 years who have used any illicit drug (other than or in addition to cannabis) in the preceding $30 \mathrm{~d}$ are eligible for study enrolment. Recruited youth are street-involved at baseline, defined as having been without stable housing or having accessed street-based services in the preceding 6 months ${ }^{(4,27,28)}$. Street-based outreach is used to enhance study recruitment both during daytime and night-time hours in a range of neighbourhoods throughout Vancouver where street youth are known to congregate. Snowball sampling is also used to maximize study enrolment. After providing informed consent, participants complete an intervieweradministered questionnaire regarding sociodemographic and socio-economic details, engagement with health and social services, substance use patterns and other behavioural data. All participants are provided with monetary compensation for their time (\$CAN 30).

The present analysis draws on baseline data from youth recruited between April 2006 and November 2013. The primary outcome of interest was depression as measured by the Center for Epidemiological Studies Depression (CES-D) scale. CES-D is a scored twenty-item survey measuring depressive symptoms ${ }^{(29)}$ that has been shown to be both valid and reliable when administered to young people $^{(30)}$ and homeless populations ${ }^{(31)}$. A cut-off of $\geq 22$ has been used successfully in previous studies as a measure of depression among high-risk populations ${ }^{(32-34)}$. The primary exposure variable of interest, food insufficiency, was based on responses to the following ARYS survey question: 'I am often hungry but I don't eat because I can't afford enough food'. Participants who responded 'never true' were compared on CES-D scores with those who responded 'sometimes true' and with those who responded 'often true'. This individual statement was extracted from a validated food insecurity scale published by Radimer/Cornell ${ }^{(35)}$. This item prompts respondents for their current hunger status and has been shown to have good specificity and sensitivity compared with dietary proxies of food insufficiency ${ }^{(36)}$. Because this population of youth experiences high rates of housing instability and homelessness, our analysis focuses on the relationship between depression and individual-level food insecurity, as opposed to household-level food insecurity.
To adjust for variables that might confound the relationship between food insufficiency and depressive symptoms, we examined an array of covariates, including: age (per year older, continuous); gender (male $v$. female); Caucasian/white ethnicity (yes $v$. no); incarceration in last 6 months (detention, prison or jail; yes $v$. no); currently in a stable relationship (legally married/common law, separated, divorced/widowed or regular partner; yes $v$. no); homelessness in the last 6 months (yes $v$. no); employment in the last 6 months (yes $v$. no); high school completion (yes $v$. no); sex work in the last 6 months (received money, gifts, food, shelter, clothes or drugs in exchange for sex; yes $v$. no); daily cocaine use in the last 6 months (yes $v$. no); daily heroin use in the last 6 months (yes $v$. no); daily meth use in the last 6 months (yes $v$. no); daily crack use in the last 6 months (yes $v$. no); any injection drug use in the last 6 months (yes $v$. no); drug or alcohol treatment in the last 6 months (yes $v$. no); and heavy alcohol use (yes $v$. no). Heavy alcohol use was defined as: $>14$ drinks/week or $>4$ drinks on one occasion for men; and $>7$ drinks/week or $>3$ drinks on one occasion for women. This measure of heavy alcohol use has been described by the National Institute on Alcohol Abuse and Alcoholism $^{(37)}$.

Initially, we examined the descriptive characteristics, stratified by depression (CES-D score $\geq 22$ ) at the first study visit. Comparisons were made using the Pearson's $\chi^{2}$ test for binary variables (Fisher's exact test when cell counts were less than or equal to 5) and the Wilcoxon rank-sum test for continuous variables. Next, we examined the bivariate associations between each explanatory variable and depression using logistic regression. As the last step, we fitted a multivariable model, considering all variables in bivariate analyses as the full model. All statistical analyses were performed using RStudio version 0.99.892 (R Foundation for Statistical Computing, Vienna, Austria). All $P$ values were two-sided and tests were considered significant at $P<0.05$.

\section{Results}

Of 1066 street-involved youth who were eligible for inclusion in the analysis, $340(31.9 \%)$ identified as female, 726 (68.1\%) identified as Caucasian/white, and the median age was 21.8 years (interquartile range $=19.9-23.6$ years). In total, $724(67.9 \%)$ reported some food insufficiency and $565(53.0 \%)$ reported CES-D score $\geq 22$. Among those who reported food insufficiency, 241 (33.3\%) reported experiencing it 'often' and $483(66.7 \%)$ reported experiencing it 'sometimes'.

Table 1 lists sociodemographic, socio-economic and substance use characteristics stratified by CES-D score $\geq 22$. Factors positively associated with depression in bivariable analyses included: food insufficiency 
Table 1 Bivariate analyses of factors associated with depression among a cohort of street-involved youth ( $n$ 1066); At-Risk Youth Study (ARYS), Vancouver, Canada, April 2006-November 2013

\begin{tabular}{|c|c|c|c|c|c|c|c|}
\hline \multirow[b]{3}{*}{ Characteristic } & \multicolumn{4}{|c|}{ CES-D score $\geq 22$} & \multirow[b]{3}{*}{ OR } & \multirow[b]{3}{*}{$95 \% \mathrm{Cl}$} & \multirow[b]{3}{*}{$P$ value } \\
\hline & \multicolumn{2}{|c|}{ Yes $(n 565,53.0 \%)$} & \multicolumn{2}{|c|}{ No $(n 501,47.0 \%)$} & & & \\
\hline & $n$ & $\%$ & $n$ & $\%$ & & & \\
\hline \multicolumn{8}{|l|}{ Food insufficiency } \\
\hline Often & 156 & $27 \cdot 6$ & 85 & $17 \cdot 0$ & $2 \cdot 75$ & $1.96,3.88$ & $<0.001$ \\
\hline Sometimes & 272 & $48 \cdot 2$ & 211 & $42 \cdot 1$ & 1.93 & $1.46,2.56$ & $<0.001$ \\
\hline Never & 137 & $24 \cdot 2$ & 205 & $40 \cdot 9$ & 1.00 & Ref. & \\
\hline \multicolumn{8}{|l|}{ Age (years) } \\
\hline Median and IQR & $21 \cdot 9$ & $20 \cdot 2-23 \cdot 6$ & $21 \cdot 7$ & $19 \cdot 5-23.5$ & 1.05 & $1 \cdot 00,1 \cdot 10$ & 0.060 \\
\hline \multicolumn{8}{|l|}{ Gender } \\
\hline Male & 356 & 63.0 & 370 & 73.9 & 0.60 & $0.46,0.78$ & $<0.001$ \\
\hline Female & 209 & 37.0 & 131 & $26 \cdot 1$ & 1.00 & Ref. & \\
\hline \multicolumn{8}{|c|}{ Caucasian/white ethnicity } \\
\hline Yes & 392 & $69 \cdot 4$ & 334 & $66 \cdot 7$ & $1 \cdot 13$ & $0.88,1.47$ & 0.343 \\
\hline No & 173 & $30 \cdot 6$ & 167 & 33.3 & 1.00 & Ref. & \\
\hline \multicolumn{8}{|l|}{ Homelessness ${ }^{*}$} \\
\hline Yes & 433 & $76 \cdot 6$ & 353 & 70.5 & 1.36 & $1.03,1.79$ & 0.029 \\
\hline No & 131 & 23.2 & 145 & 28.9 & 1.00 & Ref. & \\
\hline \multicolumn{8}{|c|}{ Currently in a stable relationship } \\
\hline Yes & 151 & $26 \cdot 7$ & 148 & 29.5 & 0.87 & $0.66,1.13$ & 0.292 \\
\hline No & 410 & $72 \cdot 6$ & 348 & 69.5 & 1.00 & Ref. & \\
\hline \multicolumn{8}{|c|}{ High school completion } \\
\hline Yes & 185 & $32 \cdot 7$ & 196 & $39 \cdot 1$ & 0.75 & $0.58,0.97$ & 0.026 \\
\hline No & 379 & $67 \cdot 1$ & 302 & $60 \cdot 3$ & 1.00 & Ref. & \\
\hline \multicolumn{8}{|l|}{ Employment* } \\
\hline Yes & 288 & $51 \cdot 0$ & 292 & $58 \cdot 3$ & 0.74 & $0.58,0.95$ & 0.017 \\
\hline No & 277 & $49 \cdot 0$ & 209 & 41.7 & 1.00 & Ref. & \\
\hline \multicolumn{8}{|l|}{ Incarceration* } \\
\hline Yes & 109 & $19 \cdot 3$ & 84 & $16 \cdot 8$ & $1 \cdot 18$ & $0.86,1.62$ & 0.292 \\
\hline No & 456 & 80.7 & 416 & 83.0 & 1.00 & Ref. & \\
\hline \multicolumn{8}{|l|}{ Daily cocaine use* } \\
\hline Yes & 21 & 3.7 & 15 & 3.0 & 1.25 & $0.64,2.46$ & 0.513 \\
\hline No & 539 & 95.4 & 482 & $96 \cdot 2$ & 1.00 & Ref. & \\
\hline \multicolumn{8}{|l|}{ Daily heroin use* } \\
\hline Yes & 69 & $12 \cdot 2$ & 34 & $6 \cdot 8$ & 1.92 & $1.25,2.95$ & 0.003 \\
\hline No & 488 & $86 \cdot 4$ & 461 & $92 \cdot 0$ & 1.00 & Ref. & \\
\hline Daily meth use* & & & & & & & \\
\hline Yes & 82 & 14.5 & 49 & $9 \cdot 8$ & 1.56 & $1 \cdot 07,2 \cdot 28$ & 0.020 \\
\hline No & 478 & 84.6 & 446 & 89.0 & 1.00 & Ref. & \\
\hline Daily crack use* & & & & & & & \\
\hline Yes & 114 & $20 \cdot 2$ & 58 & 11.6 & 1.92 & $1 \cdot 36,2 \cdot 70$ & $<0.001$ \\
\hline No & 449 & 79.5 & 438 & 87.4 & 1.00 & Ref. & \\
\hline Injection drug use* & & & & & & & \\
\hline Yes & 221 & $39 \cdot 1$ & 112 & $22 \cdot 4$ & $2 \cdot 24$ & $1.71,2.93$ & $<0.001$ \\
\hline No & 343 & $60 \cdot 7$ & 389 & $77 \cdot 6$ & 1.00 & Ref. & \\
\hline Sex work* & & & & & & & \\
\hline Yes & 89 & $15 \cdot 8$ & 26 & $5 \cdot 2$ & 3.42 & $2 \cdot 17,5 \cdot 38$ & $<0.001$ \\
\hline No & 476 & 84.2 & 475 & $94 \cdot 8$ & 1.00 & Ref. & \\
\hline Heavy alcohol use* & & & & & & & \\
\hline Yes & 201 & $35 \cdot 6$ & 195 & 38.9 & 0.86 & $0.67,1.11$ & 0.246 \\
\hline No & 362 & $64 \cdot 1$ & 303 & 60.5 & 1.00 & Ref. & \\
\hline Drug or alcohol trea & & & & & & & \\
\hline Yes & 185 & $32 \cdot 7$ & 119 & $23 \cdot 8$ & 1.56 & $1 \cdot 19,2 \cdot 05$ & 0.001 \\
\hline No & 379 & $67 \cdot 1$ & 381 & $76 \cdot 0$ & 1.00 & Ref. & \\
\hline
\end{tabular}

CES-D, Center for Epidemiological Studies Depression scale; IQR, interquartile range; Ref., reference category.

${ }^{*}$ In the last 6 months.

'sometimes'; food insufficiency 'often'; homelessness; daily heroin use; daily meth use; daily crack use; any injection drug use; sex work; and drug or alcohol treatment. Male gender, high school completion and employment were negatively associated with depression.

Table 2 shows the adjusted odds ratios (AOR) for CES-D score $\geq 22$ and variables of interest. Variables independently positively associated with depression in the multivariable analysis included: food insufficiency 'sometimes' (AOR $=1.99 ; 95 \%$ CI 1.47, 2.70); food insufficiency 'often' (AOR $=2.52 ; 95 \%$ CI 1.74, 3.67); daily crack use $(\mathrm{AOR}=1.76 ; 95 \% \mathrm{CI} 1.20,2.61)$; any injection drug use $(\mathrm{AOR}=1.81 ; 95 \% \mathrm{CI} 1.31,2.49)$; and sex work $(\mathrm{AOR}=$ $2.43 ; 95 \%$ CI 1.49, 4.09). Male gender remained negatively associated with depression ( $\mathrm{AOR}=0.61 ; 95 \%$ CI 0.45 , $0 \cdot 84)$. 
Table 2 Multivariate analysis of factors associated with depression among a cohort of street-involved youth ( $n$ 1066); At-Risk Youth Study (ARYS), Vancouver, Canada, April 2006-November 2013

\begin{tabular}{|c|c|c|c|}
\hline Variable & AOR & $95 \% \mathrm{Cl}$ & $P$ value \\
\hline \multicolumn{4}{|l|}{ Food insufficiency } \\
\hline 'Sometimes' v. 'never' & 1.99 & $1 \cdot 47,2 \cdot 70$ & $<0.001$ \\
\hline 'Often' v. 'never' & 2.52 & $1.74,3.67$ & $<0.001$ \\
\hline \multicolumn{4}{|l|}{ Age } \\
\hline Per year older, continuous & 1.03 & $0.98,1.09$ & 0.272 \\
\hline \multicolumn{4}{|l|}{ Gender } \\
\hline Male $v$. female & 0.61 & $0.45,0.84$ & 0.002 \\
\hline \multicolumn{4}{|l|}{ Caucasian/white ethnicity } \\
\hline Yes $v$. no & 1.08 & $0.81,1.43$ & 0.613 \\
\hline \multicolumn{4}{|l|}{ Homelessness* } \\
\hline Yes $v$. no & 1.05 & $0.77,1.43$ & 0.758 \\
\hline \multicolumn{4}{|l|}{ Currently in a stable relationship } \\
\hline Yes $v$. no & 0.85 & $0.63,1.15$ & 0.290 \\
\hline \multicolumn{4}{|l|}{ High school completion } \\
\hline Yes v. no & 0.83 & $0.63,1.10$ & 0.195 \\
\hline \multicolumn{4}{|l|}{ Employment ${ }^{\star}$} \\
\hline Yes $v$. no & 0.95 & $0.72,1.25$ & 0.713 \\
\hline \multicolumn{4}{|l|}{ Incarceration* } \\
\hline Yes $v$. no & 1.05 & $0.74,1.48$ & 0.805 \\
\hline \multicolumn{4}{|l|}{ Daily cocaine use* } \\
\hline Yes $v$. no & 0.86 & $0.40,1.89$ & 0.706 \\
\hline \multicolumn{4}{|l|}{ Daily heroin use* } \\
\hline Yes $v$. no & $1 \cdot 18$ & $0.72,1.95$ & 0.517 \\
\hline \multicolumn{4}{|l|}{ Daily meth use* } \\
\hline Yes $v$. no & 1.09 & $0.72,1.67$ & 0.687 \\
\hline \multicolumn{4}{|l|}{ Daily crack use* } \\
\hline Yes $v$. no & 1.76 & $1 \cdot 20,2 \cdot 61$ & 0.004 \\
\hline \multicolumn{4}{|l|}{ Injection drug use* } \\
\hline Yes $v$. no & $1 \cdot 81$ & $1.31,2.49$ & $<0.001$ \\
\hline \multicolumn{4}{|l|}{ Sex work* } \\
\hline Yes $v$. no & $2 \cdot 43$ & $1.49,4.09$ & 0.001 \\
\hline \multicolumn{4}{|l|}{ Heavy alcohol use* } \\
\hline Yes $v$. no & 1.04 & $0.78,1.37$ & 0.807 \\
\hline \multicolumn{4}{|l|}{ Drug or alcohol treatment* } \\
\hline Yes $v$. no & $1 \cdot 23$ & $0.91,1.66$ & 0.180 \\
\hline
\end{tabular}

\section{Discussion}

In the present study of street-involved youth who use illicit drugs, we observed a high prevalence of both depression and food insufficiency, with more than five in ten youth reporting CES-D score $\geq 22$, and nearly seven in ten youth reporting some level of food insufficiency. Compared with youth who reported having sufficient food, the odds of depression (CES-D score $\geq 22$ ) were higher among youth who reported any level food insufficiency. In addition, the odds of depression increased as the level of food insufficiency increased and we observed little change in these estimates after adjustment for confounders. Depression was also independently positively associated with daily crack use, injection drug use and sex work, and was independently negatively associated with male gender.

Our findings build on previous studies that have found associations between food insecurity and depression among youth ${ }^{(26,38)}$ and among adults who use injection drugs $^{(22)}$. One study using a nationally representative sample of Canadian youth found that hunger was significantly associated with future risk of depression, even after accounting for previous depressive symptoms ${ }^{(38)}$. Street-involved youth who are food insufficient often experience poverty, which has been repeatedly associated with depression ${ }^{(39,40)}$. However, one study found that while family food insufficiency was independently associated with depressive symptoms (dysthymia and suicide symptoms) among adolescents, low family income was not ${ }^{(41)}$. These findings suggest that pathways other than poverty may mediate the relationship between food insufficiency and depression. For instance, stress and anxiety have been associated with both food insecurity and depression ${ }^{(42,43)}$. Further, nutritional deficiencies ${ }^{(44)}$, shame ${ }^{(45)}$, childhood trauma ${ }^{(46)}$ and hopelessness ${ }^{(47)}$ have all been associated with symptoms of depression and may mediate this relationship. There is also evidence of a bidirectional relationship between food insecurity and depression $^{(48)}$, which may suggest that depression contributes to food insecurity in street-involved youth by acting as a barrier to services ${ }^{(49)}$ or by impeding the purchase and preparation of meals. The associations found in 
the current analysis between depression and daily crack use, injection drug use and female gender are consistent with what has previously been found in the literature ${ }^{(50,51)}$.

The findings from the current study suggest that there is a need to increase access to quality mental health and food security interventions among this population of youth. Previous studies have found that street-involved youth experience high rates of mental illness ${ }^{(16,17)}$. The high-risk environment and trauma associated with living or working on the streets often intensify pre-existing mental health issues and make it challenging for clinicians to diagnose youth appropriately ${ }^{(52)}$. In addition to these high rates of mental health issues, unstably housed youth face many barriers to care including fear of discrimination, long waiting lists and lack of specialized youth services $^{(53-56)}$. Further, due to the large nutritional gap that still exists for Canada's most vulnerable populations, food security interventions (e.g. food banks) are often unable to meet demands ${ }^{(57)}$ and some homeless youth have described food assistance programmes to be of poor quality and associated with food sickness ${ }^{(58)}$.

Because of the tremendous health and economic burden associated with both food insecurity and mental illness, it is critical that policies and programmes focus on the social and environmental determinants of food access, such as formal employment (hindered by factors such as educational limitations, discrimination and incarceration) ${ }^{(17)}$ and stable housing (hindered by factors such as family breakdown, abuse and 'ageing out' of the foster care system) ${ }^{(52)}$. It is also important that mental health programmes consider how food insufficiency may act as an underlying cause or contributing factor to depression, and that interventions addressing food insecurity gain capacity to support youth who are experiencing mental illness and refer them to appropriate services. There is evidence that social support may moderate the relationship between food insufficiency and depression ${ }^{(21,59)}$, which highlights the potential benefits of incorporating social support interventions into food security programmes.

There are limitations to the present study. First, because it is a cross-sectional study, we are unable to determine the direction of the relationship between food insufficiency and depression. Second, our sample was not randomly selected (as there are no registries of street youth to draw upon) and included only youth who had used illicit drugs in the $30 \mathrm{~d}$ prior to baseline. Therefore, our sample may not be representative of all street youth in Vancouver. However, we note that the characteristics of the ARYS sample are similar to those from other studies of high-risk youth $^{(60-62)}$. Third, we relied on self-report, which may have been subject to response biases, including recall bias and socially desirable responding, although we know of no reason why this would explain the associations we identified in our study. Fourth, the Radimer/Cornell scale is no longer frequently used in food security research, as newer scales such as the Household Food Security Survey Module (HFSSM) ${ }^{(63)}$ have been developed. However, we note that the individual item on the Radimer/Cornell scale used in the current study has been incorporated into several recently developed food insecurity scales (including the HFSSM) and has remained relatively consistent across them ${ }^{(64)}$. Lastly, the current study did not include a detailed analysis of race or ethnicity. To control for confounding, we included an 'ethnicity' variable that was limited to 'Caucasian/white' $v$. 'other'. However, given that youth who identify as 'non-white' are more likely to experience unstable housing relative to youth who identify as 'white ${ }^{,(65)}$, and that race has previously been associated with food insecurity ${ }^{(6)}$, it would have been useful to further examine whether race/ethnicity has a modifying effect on the relationship between food insufficiency and depression.

To our knowledge, the present study is the first to document a relationship between food insufficiency and depression among street-involved youth who use illicit drugs. These findings call attention to the limitations of current food security interventions in meeting their nutritional needs, as well as the importance of addressing structural factors that contribute to the high rates of food insufficiency within this population. The current study also highlights the importance of addressing the mental health concerns of youth who are already food insufficient. Further research is needed to identify potential pathways by which food insufficiency may lead to depression and how depression may lead to further food insufficiency by hindering access to food supplies and/or nutritional support programmes.

\section{Acknowledgements}

Acknowledgements: The authors thank the study participants for their contribution to the research, as well as current and past researchers and staff. Financial support: The study was supported by the US National Institutes of Health (grant number U01DA038886). K.D. is supported by a Michael Smith Foundation for Health Research/St. Paul's Hospital Foundation-Providence Health Care Career Scholar Award and a Canadian Institutes of Health Research New Investigator Award. This research was undertaken, in part, thanks to funding from the Canada Research Chairs programme through a Tier 1 Canada Research Chair in Inner City Medicine which supports Dr Evan Wood. The funding agencies had no role in the design, analysis or writing of this article. Conflict of interest: The authors declare no conflicts of interest. Authorship: J.G.-H., K.D. and T.K. conceptualized the study design. E.N. performed the statistical analyses, and J.G.-H. and T.K. interpreted the results. J.G.-H. drafted the initial manuscript. T.K., K.D. and L.D. provided substantial revisions of the manuscript and guidance throughout the 
writing. All authors have read and approved the final manuscript. Ethics of human subject participation: This study was conducted according to the guidelines laid down in the Declaration of Helsinki and all procedures involving human subjects were approved by the University of British Columbia and Providence Health Care Research Ethics Board. Written informed consent was obtained from all subjects.

\section{References}

1. Barker B, Kerr T, Dong H et al. (2017) History of being in government care associated with younger age at injection initiation among a cohort of street-involved youth. Drug Alcohol Rev 36, 639-642.

2. Hayashi K, Daly-Grafstein B, Dong H et al. (2016) The relationship between violence and engagement in drug dealing and sex work among street-involved youth. Can J Public Health 107, e88-e93.

3. Krusi A, Fast D, Small W et al. (2010) Social and structural barriers to housing among street-involved youth who use illicit drugs. Health Soc Care Community 18, 282-288.

4. Boivin JF, Roy E, Haley N et al. (2005) The health of street youth: a Canadian perspective. Can J Public Health 96, 432-437.

5. Roy E, Haley N, Leclerc P et al. (2004) Mortality in a cohort of street youth in Montreal. JAMA 292, 569-574.

6. Tarasuk V, Dachner N, Poland B et al. (2009) Food deprivation is integral to the 'hand to mouth' existence of homeless youths in Toronto. Public Health Nutr 12, $1437-1442$.

7. Whitbeck LB, Chen X \& Johnson KD (2006) Food insecurity among homeless and runaway adolescents. Public Health Nutr 9, 47-52.

8. Kirkpatrick SI \& Tarasuk V (2008) Food insecurity is associated with nutrient inadequacies among Canadian adults and adolescents. J Nutr 138, 604-612.

9. Smith C \& Richards R (2008) Dietary intake, overweight status, and perceptions of food insecurity among homeless Minnesotan youth. Am J Hum Biol 20, 550-563.

10. Tarasuk V, Dachner N \& Li J (2005) Homeless youth in Toronto are nutritionally vulnerable. J Nutr 135, 1926-1933.

11. Crews DC, Kuczmarski MF, Grubbs V et al. (2014) Effect of food insecurity on chronic kidney disease in lower-income Americans. Am J Nephrol 39, 27-35.

12. Davison KM, Gondara L \& Kaplan BJ (2017) Food insecurity, poor diet quality, and suboptimal intakes of folate and iron are independently associated with perceived mental health in Canadian adults. Nutrients 9, E274.

13. Jones AD (2017) Food insecurity and mental health status: a global analysis of 149 countries. Am J Prev Med 53, 264-273.

14. Sirotin N, Hoover DR, Shi Q et al. (2014) Food insecurity with hunger is associated with obesity among HIV-infected and at risk women in Bronx, NY. PLoS One 9, e105957.

15. Seligman HK, Bindman AB, Vittinghoff E et al. (2007) Food insecurity is associated with diabetes mellitus: results from the National Health Examination and Nutrition Examination Survey (NHANES) 1999-2002. J Gen Intern Med 22, 1018-1023.

16. Ensign J \& Santelli J (1998) Health status and service use: comparison of adolescents at a school-based health clinic with homeless adolescents. Arch Pediatr Adolesc Med 152, 20-24.

17. Gwadz MV, Gostnell K, Smolenski C et al. (2009) The initiation of homeless youth into the street economy. $J$ Adolesc 32, 357-377.
18. Campbell CC (1991) Food insecurity: a nutritional outcome or a predictor variable? J Nutr 121, 408-415.

19. Scott RI \& Wehler CA (1998) Food insecurity/food insufficiency: an empirical examination of alternative measures of food problems in impoverished US households. Institute for Research on Poverty Discussion Paper no. 1176-98. https:// www.irp.wisc.edu/publications/dps/pdfs/dp117698.pdf (accessed September 2018).

20. Heylen E, Panicker ST, Chandy S et al. (2015) Food insecurity and its relation to psychological well-being among South Indian people living with HIV. AIDS Behav 19, 1548-1558.

21. Kapulsky L, Tang AM \& Forrester JE (2015) Food insecurity, depression, and social support in HIV-infected Hispanic individuals. J Immigr Minor Health 17, 408-413.

22. Anema A, Wood E, Weiser SD et al. (2010) Hunger and associated harms among injection drug users in an urban Canadian setting. Subst Abuse Treat Prev Policy 5, 20.

23. Dewing S, Tomlinson M, le Roux IM et al. (2013) Food insecurity and its association with co-occurring postnatal depression, hazardous drinking, and suicidality among women in peri-urban South Africa. J Affect Disord 150, 460-465.

24. Montgomery J, Lu J, Ratliff S et al. (2017) Food insecurity and depression among adults with diabetes: results from the National Health and Nutrition Examination Survey (NHANES). Diabetes Educ 43, 260-271.

25. McIntyre L, Williams JV, Lavorato DH et al. (2013) Depression and suicide ideation in late adolescence and early adulthood are an outcome of child hunger. J Affect Disord 150, 123-129.

26. Romo ML, Abril-Ulloa V \& Kelvin EA (2016) The relationship between hunger and mental health outcomes among school-going Ecuadorian adolescents. Soc Psychiatry Psychiatr Epidemiol 51, 827-837.

27. DeMatteo D, Major C, Block B et al. (1999) Toronto street youth and HIV/AIDS: prevalence, demographics, and risks. J Adolesc Health 25, 358-366.

28. Kerr T, Marshall BD, Miller C et al. (2009) Injection drug use among street-involved youth in a Canadian setting. BMC Public Health 9, 171.

29. Radloff LS (1977) The CES-D scale: a self-report depression scale for research in the general population. Appl Psychol Meas 1, 385-401.

30. Radloff LS (1991) The use of the Center for Epidemiologic Studies Depression Scale in adolescents and young adults. $J$ Youth Adolesc 20, 149-166.

31. Fitzpatrick KM, Irwin J, Lagory M et al. (2007) Just thinking about it: social capital and suicide ideation among homeless persons. J Health Psychol 12, 750-760.

32. Hallfors DD, Waller MW, Bauer D et al. (2005) Which comes first in adolescence - sex and drugs or depression? Am J Prev Med 29, 163-170.

33. Sutcliffe CG, German D, Sirirojn B et al. (2009) Patterns of methamphetamine use and symptoms of depression among young adults in northern Thailand. Drug Alcohol Depend 101, 146-151.

34. Weissman MM, Sholomskas D, Pottenger M et al. (1977) Assessing depressive symptoms in five psychiatric populations: a validation study. Am J Epidemiol 106, 203-214.

35. Radimer KL, Olson CM \& Campbell CC (1990) Development of indicators to assess hunger. J Nutr 120, Suppl. 11, $1544-1548$.

36. Kendall A, Olson CM, Frongillo EA Jr (1995) Validation of the Radimer/Cornell measures of hunger and food insecurity. J Nutr 125, 2793-2801.

37. Willenbring ML, Massey SH \& Gardner MB (2009) Helping patients who drink too much: an evidence-based guide for primary care clinicians. Am Fam Physician 80, 44-50. 
38. McIntyre L, Wu X, Kwok C et al. (2017) The pervasive effect of youth self-report of hunger on depression over 6 years of follow up. Soc Psychiatry Psychiatr Epidemiol 52, 537-547.

39. Catz SL, Gore-Felton C \& McClure JB (2002) Psychological distress among minority and low-income women living with HIV. Behav Med 28, 53-60.

40. Wu DY, Munoz M, Espiritu B et al. (2008) Burden of depression among impoverished HIV-positive women in Peru. J Acquir Immune Defic Syndr 48, 500-504.

41. Alaimo K, Olson CM \& Frongillo EA (2002) Family food insufficiency, but not low family income, is positively associated with dysthymia and suicide symptoms in adolescents. J Nutr 132, 719-725.

42. Williamson DE, Birmaher B, Anderson BP et al. (1995) Stressful life events in depressed adolescents: the role of dependent events during the depressive episode. $J \mathrm{Am}$ Acad Child Adolesc Psychiatry 34, 591-598.

43. Maynard MS, Perlman CM \& Kirkpatrick SI (2017) Food insecurity and perceived anxiety among adolescents: an analysis of data from the 2009-2010 National Health and Nutrition Examination Survey (NHANES). J Hunger Environ Nutr. Published online: 14 December 2017. doi: 10.1080/19320248.2017.1393363.

44. Cabrera MA, Mesas AE, Garcia AR et al. (2007) Malnutrition and depression among community-dwelling elderly people. $J$ Am Med Dir Assoc 8, 582-584.

45. Andrews B, Qian M \& Valentine JD (2002) Predicting depressive symptoms with a new measure of shame: the Experience of Shame Scale. Br J Clin Psychol 41, 29-42.

46. Hadland SE, Marshall BD, Kerr T et al. (2012) Suicide and history of childhood trauma among street youth. $J$ Affect Disord 136, 377-380.

47. Kuo WH, Gallo JJ \& Eaton WW (2004) Hopelessness, depression, substance disorder, and suicidality - a 13-year community-based study. Soc Psychiatry Psychiatr Epidemiol 39, 497-501.

48. Huddleston-Casas C, Charnigo R \& Simmons LA (2009) Food insecurity and maternal depression in rural, lowincome families: a longitudinal investigation. Public Health Nutr 12, 1133-1140.

49. Aviles A \& Helfrich C (2004) Life skill service needs: perspectives of homeless youth. $J$ Youth Adolesc 33, 331-338.

50. Hadland SE, Marshall BD, Kerr T et al. (2011) Depressive symptoms and patterns of drug use among street youth. $J$ Adolesc Health 48, 585-590.

51. Pettes T, Kerr T, Voon P et al. (2015) Depression and sexual risk behaviours among people who inject drugs: a genderbased analysis. Sex Health 12, 224-230.

52. Edidin JP, Ganim Z, Hunter SJ et al. (2012) The mental and physical health of homeless youth: a literature review. Child Psychiatry Hum Dev 43, 354-375.
53. Christiani A, Hudson AL, Nyamathi A et al. (2008) Attitudes of homeless and drug-using youth regarding barriers and facilitators in delivery of quality and culturally sensitive health care. J Child Adolesc Psychiatr Nurs 21, 154-163.

54. Hudson AL, Nyamathi A, Greengold B et al. (2010) Healthseeking challenges among homeless youth. Nurs Res 59, 212-218.

55. Reid S, Berman H \& Forchuk C (2005) Living on the streets in Canada: a feminist narrative study of girls and young women. Issues Compr Pediatr Nurs 28, 237-256.

56. Hadland SE, Kerr T, Li K et al. (2009) Access to drug and alcohol treatment among a cohort of street-involved youth. Drug Alcohol Depend 101, 1-7.

57. Tarasuk V, Dachner N \& Loopstra R (2014) Food banks, welfare, and food insecurity in Canada. Br Food $J$ 116, $1405-1417$.

58. Dachner N \& Tarasuk V (2002) Homeless 'squeegee kids': food insecurity and daily survival. Soc Sci Med 54, 1039-1049.

59. Tsai AC, Tomlinson M, Comulada WS et al. (2016) Food insufficiency, depression, and the modifying role of social support: evidence from a population-based, prospective cohort of pregnant women in peri-urban South Africa. Soc Sci Med 151, 69-77.

60. Evans JL, Hahn JA, Lum PJ et al. (2009) Predictors of injection drug use cessation and relapse in a prospective cohort of young injection drug users in San Francisco, CA (UFO Study). Drug Alcohol Depend 101, 152-157.

61. Ochnio JJ, Patrick D, Ho M et al. (2001) Past infection with hepatitis A virus among Vancouver street youth, injection drug users and men who have sex with men: implications for vaccination programs. CMAJ 165, 293-297.

62. Steensma C, Boivin JF, Blais L et al. (2005) Cessation of injecting drug use among street-based youth. J Urban Health 82, 622-637.

63. US Department of Agriculture (2017) US Household Food Security Survey Module; US Adult Food Security Survey Module. https://www.ers.usda.gov/topics/food-nutritionassistance/food-security-in-the-us/survey-tools/ (accessed July 2018)

64. US Department of Agriculture (2006) Food insecurity and hunger in the United States: An assessment of the measure. Panel to Review the US Department of Agriculture's Measurement of Food Insecurity and Hunger. http://www.nap. edu/catalog/11578.html (accessed Jul 2018).

65. Fowler PJ, Toro PA \& Miles BW (2009) Pathways to and from homelessness and associated psycho-social outcomes among adolescents leaving the foster care system. Am J Public Health 99, 1453-1458.

66. Myers AM \& Painter MA II (2017) Food insecurity in the United States of America: an examination of race/ethnicity and nativity. Food Secur 9, 1419-1432. 